\title{
Cytokine profiles during experimental Chagas' disease
}

\section{M.J.F. Morato', \\ D.G. Colley ${ }^{2}$ and M.R. Powell ${ }^{2}$}

Correspondence

M.J.F. Morato

Laboratório de Imunologia Celular

e Molecular

Centro de Pesquisas René Rachou FIOCRUZ

Av. Augusto de Lima, 1715

30190-002 Belo Horizonte, MG

Brasil

Fax: 55 (031) 295-3115

Presented at the International Meeting on Cytokines, Angra dos Reis, RJ, Brasil, November 24-28, 1996.

Received September 24, 1997 Accepted September 30, 1997

\author{
'Laboratório de Imunologia Celular e Molecular, Centro de Pesquisas René Rachou, \\ FIOCRUZ, Belo Horizonte, MG, Brasil \\ ${ }^{2}$ Division of Parasitic Diseases, NCID, Centers for Disease Control and Prevention, \\ Atlanta, GA, USA
}

\section{Abstract}

People infected with Trypanosoma cruzi remain so for life, yet only $30-40 \%$ of these individuals develop characteristic chagasic cardiomyopathies. Similarly, when infected with the Brazilian strain of $T$. cruzi, $D B A / 2$ mice develop severe cardiac damage while B10.D2 $m$ ice do not. To better understand the immunological parameters that may be involved in the disease process, we have used this murine model (DBA/2 vs B 10.D2) and compared the changes in cytokine production during the course of infection with $T$. cruzi. Concanavalin $A$ (Con A) stimulation of spleen cells harvested during the acute phase (day 30) resulted in similarly high levels of IFN- $\gamma$ in both mouse strains. However, the amount of $I F N-\gamma$ in supernatants from cultures of B 10.D2 spleen cells initiated during the chronic phase (day 72) was at subacute levels, whereas secretion by chronic $D B A / 2$ spleen cells remained high. In addition, Con $A$-stimulated spleen cells from acute $D B A / 2 m$ ice prod $u$ ced $a$ pproxi $m a t e l y$ twice $a s m u$ ch $I L-10$ and significantly more $I L-4$ than cells from B 10.D2 mice. $I L-4$ secretion remained low by cells from chronic B 10.D2 mice, but when using cells from chronic $D B A / 2$ mice, levels continued to increase beyond the already high levels secreted by cells harvested during the acute phase. Proliferative responses to Con $A$ stimulation by spleen cells from $D B A / 2 \mathrm{mice}$ were significantly higher than those from B $10 . D 2 \mathrm{mice}$ in $b$ oth the acute and chronic phases. These data suggest that enhanced responses in $D B A / 2$ mice, which may be related to $a$ higher parasite burden, a lack of down-regulation, and/or the onset of autoimmune phenomena, correlate with the more severe cardiomyopathy seen in pathopermissive mice.

Trypanosoma cruzi is an obligate intracellular protozoan parasite of humans and other mammals and is the causative agent of Chagas' disease. During the acute phase of infection parasites are detectable in the $b$ lood, although the level of parasitemia is often low. The subsequent chronic phase is characterized by a decrease in the number of circulating parasites to levels that are usually not detectable, even though the host remains
Key words

- Experimental Chagas' disease

- Trypanosoma cruzi

- Cytokines

- IFN- $\gamma$

- IL-10

- IL-4 - 1 -

infected for life. The host's immune response also changes as the infection progresses from the acute to the chronic phase and is likely to be related to major shifts in cytokine prod $u$ ction.

Using a comparative genetic model, we have previously shown that both the levels and the kinetics of cytokine production differ in strains of mice that differ in their $a b$ ility to survive acute infection, suggesting 
their importance in resistance (1). For example, we demonstrated that antigen-stimulated spleen cells from mice that express the resistant $H-2^{q} M H C$ haplotype prod $u$ ced significantly more interferon-gamma (IFN- $\gamma)$ than cells from mice that share the susceptible $H-2^{k}$ haplotype. However, spleen cells from susceptible and resistant $m$ ice prod $u$ ced similar levels of $I F N-\gamma$ when stimulated with concanavalin $A$ (Con $A$ ), suggesting that the potential to $\operatorname{prod} u$ ce this critical cytokine is similar in both resistant and susceptible strains, but that parasite-ind $u$ ced regulatory events down-regulate production in the susceptible mice. This may be related to the secretion of $I L-10$, which we found to $b$ e inversely correlated with $I F N-\gamma$ levels throughout the course of acute infection. However, we found this inverse correlation of cytokine levels in supernatants from Con $A$-stimulated spleen cells from both resistant and susceptible strains. In addition, we found that cytokine prod $u$ ction by lym ph node cells differs from production by splenocytes. These results support those of others (2) who demonstrated that cytokine-prod $u$ cing cells are compartmentalized in different lymphoid organs during acute $T$. cruzi infection and further emphasize the complexity of immunoregulation during this disease.

More recently, we have examined immunological phenomen $a$ during both the acute and the chronic phase of $T$. cruzi infection. In these $s t u$ dies we compared in vitro cytokine production and changes in cell phenotype (Morato MJF, Freeman GL, Colley $D G$ and Powell $M R, u$ npublished data) in $D B A / 2$ and B 10.D2 mice after infection with the Brazilian strain of $T$. cruzi. DBA/2 mice develop high parasitemia during the acute phase and subsequently develop severe cardiomyopathy, and are termed pathopermissive (3). Conversely, B 10.D2 do not develop high levels of circulating parasites or severe cardiac damage and are thus termed pathoresistant. $W$ e measured the levels of $I F N-\gamma, I L-$ 4 , and $I L-10$ prod $u$ ced by spleen cells from each of these strains after stimulation in vitro. Studies during the acute phase were done using cells from mice infected for 21 or 30 days. In the chronic phase, we harvested cells from mice infected for 72-75 days, $a$ time when differences in the degree of cardiac pathology between the two strains is demonstrable.

Splenocytes from both strains of mice infected for 21 days, when stimulated in vitro with $C$ on $A$, secreted significantly higher levels of $I F N-\gamma(>80 \mathrm{U} / \mathrm{ml})$ compared to noninfected controls. Thirty days after infection, the levels secreted by spleen cells from both strains of mice were also similar, but had increased dramatically to $>300 \mathrm{U} / \mathrm{ml}$. However, during the chronic phase (72 days after infection) the amount of $I F N-\gamma$ secreted by cells from pathoresistant mice had declined to lower levels than those found in the acute phase $(<50 \mathrm{U} / \mathrm{ml})$, whereas the quantity secreted by pathopermissive mice was sustained $a t>300 \mathrm{U} / \mathrm{ml}$. Since at this time point (day 72) the numbers of circulating parasites have reached essentially undetectable levels in the blood of both strains of mice, these results suggest that the continuing inflammatory response may be related to $a$ lack of down-regulation in pathopermissive mice, that there are increased levels of parasites sequestered in the solid tissues, and/or that autoimmune mechanisms are responsible for stimulating ongoing unchecked immunologi$\mathrm{c} a \mathrm{l}$, and potentially immunopathological, phenomena.

Con $A$ stimulation of spleen cells prepared from both mouse strains during the acute phase (day 30) also resulted in enhanced $I L-10$ secretion. These results are consistent with other st $u$ dies that have shown concurrent secretion of both inflammatory (TH1) and anti-inflammatory (TH2) cyto$k$ ines during T. cruzi infection (4-7), incl $u$ ding an analysis of cytokine $m R N A$ expression in hearts from B 10.D2 and DBA/2 mice (Powell MR, Morgan $J M$ and Colley $D G$, $u$ npublished data). Moreover, it should be 
noted that the levels of $I L-10$ detected in culture supernatants from Con $A$-stimulated $D B A / 2$ spleen cells (day 30) contained twice as $m u$ ch $I L-10$ compared to their pathoresistant B 10.D2 counterparts. Y et the levels of $I F N-\gamma$, which are known to usually be in$v$ ersely related to $I L-10(7-9)$, were similar in cultures from the two strains at this time $\mathrm{d} u r i n g$ the $a \mathrm{c} u$ te phase. $I L-10$ prod $u$ ction by cells from both strains of $m$ ice diminished to near control levels in cultures prepared on day 72 after infection, but cells from chronic $D B A / 2$ mice contin $u$ ed to secrete $I F N-\gamma$ while cells from B 10.D2 mice did not (see above), suggesting that different pathways of cytokine regulation may be occurring in these two strains of mice. This is further supported by the fact that spleen cells from $D B A / 2$ $m$ ice harvested 30 days after infection secrete little $I L-10$ upon in vitro stimulation with $L P S$, whereas B 10.D2 mice secrete copious quantities under the same conditions. This result indicates that, if $I L-10$ plays a role in cardiac pathogenesis (or the prevention thereof) in these mice, it may be derived from different sources.

Stimulation of spleen cells from infected $D B A / 2$ mice with Con $A$ also resulted in significantly enhanced secretion of $I L-4$. $L$ evels of $>300 \mathrm{pg} / \mathrm{ml}$ were found in supernatants using cells from mice infected for 30 days, which increased to $>800 \mathrm{pg} / \mathrm{ml}$ when cells from mice infected for $72-75$ days were used. Spleen cells from B 10.D2 mice did not secrete $I L-4$, regardless of the time point after infection when the cells were harvested. In addition, proliferative responses, measured by $\left[{ }^{3} H\right]$-thymidine incorporation after Con $A$ stimulation of spleen cells from $D B A$ / 2 mice, were elevated on day $30(E / C=12)$ and even higher on day $75(E / C=57)$, while proliferation of B 10.D2 spleen cells was low $(E / C<3)$ throughout the course of infection.

Taken together, these data suggest that $a$ vigorous immune response in pathopermissive mice, not seen in the pathoresistant strain, may contribute to the severe pathogenesis found in these animals. Such an over-zealous response may be related to the lack of immunoregulation, $a$ higher level of parasite burden (3), and/or the onset of $a u$ toimmune phenomena (10). Further study of this model should contribute to a better understanding of which of these mechanisms are related to the development and/or prevention of chronic chagasic cardiomyopathy.

\section{References}

1. Eksi S, Wasson DL \& Powell MR (1996). Host genetics and resistance to acute Trypanosoma cruzi infection in mice: profiles and compartmentalization of IL-2-, -4-, -5-, -10- and IFN- $\gamma$-producing cells. Journal of Parasitology, 82: 59-65

2. Vandekerckhove F, Darji A, Rivera M-T, Carlier Y, Vray B, Billiau A \& De Baetselier $P$ (1994). Modulation of T-cell responsiveness during Trypanosoma cruzi infection: Analysis in different lymphoid compartments. Parasite Immunology, 16: 77-85

3. Rowland EC, Lozykowski MG \& McCormick TS (1992). Differential cardiac histopathology in inbred mouse strains chronically infected with Trypanosoma cruzi. Journal of Parasitology, 78: 10591066.
4. Zhang $L$ \& Tarleton $R L$ (1996). Characterization of cytokine production in murine Trypanosoma cruzi infection by in situ immunocytochemistry: Lack of association between susceptibility and type 2 cytokine production. European Journal of Immunology, 26: 102-109.

5. Zhang $L$ \& Tarleton $R L$ (1996). Persistent production of inflammatory and anti-inflammatory cytokines and associated $\mathrm{MHC}$ and adhesion molecule expression at the site of infection and disease in experimental Trypanosoma cruzi infections. Experimental Parasitology, 84: 203-213.

6. Laucella S, Salcedo R, Castanos-Velez E, Riarte A, De Tito EH, Patarroyo M, Orn A \& Rottenberg ME (1996). Increased expression and secretion of ICAM-1 during experimental infection with Trypanosoma cruzi. Parasite Immunology, 18: 227-239.
7. Silva JS, Morrissey PJ, Grabstein KH, Mohler KM, Anderson D \& Reed SG (1992). Interleukin 10 and interferon $\gamma$ regulation of experimental Trypanosoma cruzi infection. Journal of Experimental Medicine, 175: 169-174.

8. Reed SG, Brownell CE, Russo DM, Silva JS, Grabstein KH \& Morrissey PJ (1994). IL-10 mediates susceptibility to Trypanosoma cruzi infection. Journal of Immunology, 153: 3135-3140

9. Street NE \& Mosmann TR (1991). Functional diversity of $T$ lymphocytes due to secretion of cytokine patterns. FASEB Journal, 5: 171-177.

10. Tanowitz HB, Kichhoff LV, Simon D, Morris SA, Weiss LM \& Wittner M (1992). Chagas' disease. Clinical Microbiology Reviews, 5: 400-419. 